\title{
Os Ciclos Político-Econômicos e os Gastos dos Estados no Brasil: 1995-2013
}

\author{
Daniel Guerra ${ }^{1}$ \\ Adriano Nascimento da Paixão ${ }^{2}$ \\ Paulo Amilton Maia Leite Filho ${ }^{3}$ \\ ${ }^{1}$ Ministério Público do Estado da Paraíba. João Pessoa, PB, Brasil. (e-mail: \\ danieleconomia@hotmail.com); \\ 2 Universidade Federal da Paraíba. João Pessoa, PB, Brasil. (e-mail: anpaixao@gmail.com); \\ ${ }^{3}$ Universidade Federal da Paraíba. João Pessoa, PB, Brasil. (e-mail: pmaiaf@hotmail.com)
}

\section{INTRODUÇ̃̃o}

\begin{abstract}
A análise em torno da relevância das eleições e da ideologia partidária nos resultados macroeconômicos tem se tornado assunto de extrema importância no debate econômico atual. Tal análise passou a figurar com mais intensidade nas discussões econômicas a partir dos trabalhos seminais desenvolvidos na década de 1970 por Nordhaus (1975) e Hibbs (1977), que haviam sido precedidos por Downs (1957), cujas formulações impulsionaram os estudos na linha de pesquisa conhecida como ciclos político-econômicos (political business cycles).

Estudos internacionais têm constatado vinculações entre a agenda eleitoral e a dinâmica das variáveis de gasto público estatais. Estudos empíricos têm testado a influência que o calendário eleitoral exerce sobre a execução fiscal e as despesas públicas regionais e têm encontrado que os governos são conduzidos de forma oportunista. Tais estudos demonstram que os gastos públicos tendem a aumentar em anos eleitorais e declinar nos anos pós-eleitorais. Jula e Jula (2007) demonstraram a presença de PBC (Political Businnes Cycles) na política orçamentária dos municípios da Romênia. Tal constatação também foi feita por Gámez e Ibarra-Yúnez (2009) para os gastos nos estados mexicanos, por Drazen e Eslava (2003), para os gastos dos estados da Colômbia e por Veiga (2004) para os municípios portugueses. No Brasil, Cossio

DADOS - Revista de Ciências Sociais, Rio de Janeiro, vol. 61, no3, 2018, pp. 695 a 734.
\end{abstract}

http://dx.doi.org/10.1590/001152582018171

695 
(2001) e Sakurai (2009), identificaram padrões oportunistas para as despesas de estados e municípios brasileiros.

Com efeito, Rogoff (1990) salienta que a teoria de ciclos políticos orçamentários sugere que seria mais promissor concentrar a pesquisa empírica sobre testes para os ciclos eleitorais nos impostos, transferências e gastos de consumo do governo. Propõe testar os dados para as eleições estaduais e locais, em vez de se concentrar apenas no pequeno número de observações disponíveis para as eleições nacionais.

Apesar de as pesquisas em torno dos ciclos políticos econômicos estarem em franco desenvolvimento em outros países, ainda há uma relativa escassez de trabalhos publicados nessa área no Brasil. A carência de trabalhos com este enfoque no Brasil, contrasta com a exposição constante nos meios de comunicação de temas relacionados ao uso da máquina pública nas eleições. Aparentemente, o uso da manipulação de políticas econômicas na forma preconizada pelo modelo oportunista, ou seja, com ampliação dos gastos e investimentos ao final dos mandatos, é uma prática corriqueira no país.

Diante desse quadro, este trabalho tem como objetivo central verificar se existem evidências empíricas de Ciclos Político-Econômicos para os governos estaduais do Brasil, analisando-se as políticas fiscais e resultados eleitorais no período de 1995 a 2013. Assim, procurando suprir a lacuna existente de estudos empíricos sobre esse tema, buscar-se-á verificar se os governos estaduais manipulam os gastos públicos como medida de sinalizar competência diante dos eleitores para com isso ampliar as chances de vitória eleitoral do candidato/ partido no poder. Desse modo, a principal hipótese a ser testada neste trabalho é que os governos empregam políticas fiscais expansionistas próximos quando às eleições e restritivas no início dos mandatos. Secundariamente será verificado se os gastos são afetados por razões ideológico-partidárias.

Destaca-se que o presente trabalho, além analisar um período de tempo maior e mais recente ainda não estudado, atualiza e preenche um vazio existente na literatura. Além disso, amplia-se a análise da manipulação da política fiscal dos estados brasileiros em relação a várias funções-despesas, para as três composições ideológicas adotadas - direita, esquerda e centro. Esta abordagem traz uma inovação em relação a outros trabalhos que objetivaram estudar o referido tema, pois, em geral, se limitaram apenas a averiguar variáveis fiscais agregadas ou separaram as diferenças partidárias apenas entre os extremos ideoló- 
gicos da esquerda e da direita, como adotado em Sakurai (2009) e Cossio (2001). A classificação dos partidos apenas nos dois polos ideológicos, no caso brasileiro, não parece ser a técnica mais apropriada e pode induzir a resultados e interpretações inconsistentes. Além disso, este artigo possui um aspecto metodológico que se diferencia de outros trabalhos existentes na literatura nacional. Sakurai (idem) e Cossio (idem), ao contrário deste artigo, analisaram o comportamento dos gastos de municípios e estados, limitando o comparativo apenas entre o ano eleitoral frente a todos os demais anos das gestões dos Executivos municipal e estadual, o que impediu a avaliação do desempenho do ciclo orçamentário completo, como foi feito neste artigo.

Para abordar as questões propostas relacionadas ao Ciclo Político-Econômico nas gestões orçamentárias estaduais e atingir os objetivos delineados acima, o texto está organizado da seguinte forma: na próxima seção é feita uma breve revisão da teoria discorrendo-se sobre as diferentes abordagens acerca de ciclos político-econômicos, além de ser feita uma revisão nos trabalhos empíricos já realizados no Brasil e no exterior acerca desse tema; na terceira seção é apresentada a metodologia indicando-se o modelo econométrico adotado e os dados que foram utilizados na pesquisa; na quarta parte os resultados das estimações são apresentados e discutidos. Em seguida é apresentada a conclusão com as considerações sobre os resultados encontrados no trabalho e encaminhamentos para a pesquisa na área.

\section{REVISÃO DA TEORIA E EVIDÊNCIAS EMPÍRICAS}

Os distintos modelos teóricos de CPE possuem uma essência comum, sua base é a vinculação das políticas econômicas e seus consequentes resultados a interesses eleitorais e de projetos de poder político. Borsani (2001) resume em três pressupostos básicos o modelo de ciclos eleitorais:

- o principal objetivo dos partidos no governo é manter-se no poder, por isso intervêm na situação econômica a fim de maximizar votos na próxima eleição;

- os resultados eleitorais dependem de forma significativa dos resultados econômicos; e

- os governos podem, mediante suas decisões e instrumentos de política pública, gerar, antes das eleições, mais crescimento produtivo assim como a diminuição do desemprego para níveis não sustentá-

DADOS - Revista de Ciências Sociais, Rio de Janeiro, vol. 61, n 3, 2018 
veis a médio prazo, à custa de um aumento da inflação no período pós-eleitoral.

A diferença entre os modelos de CPE ocorre fundamentalmente nas motivações dos partidos/governantes e na racionalidade dos agentes. Um primeiro enfoque que será utilizado neste trabalho supõe que os governantes são eminentemente oportunistas, de modo que suas ações são voltadas exclusivamente para a obtenção e a permanência no poder.

Uma segunda abordagem pressupõe que os partidos são impelidos por motivações ideológicas. Neste caso, existem diferenças nas funções utilidades dos partidos: em geral os partidos de esquerda tendem a ser mais coniventes com a inflação e/ou déficit fiscal, enquanto os partidos de direita seriam mais refratários em relação ao excesso de gasto.

O segundo ponto que distingue os modelos de CPE encontra-se na hipótese adotada quanto à formação das expectativas dos agentes. O modelo tradicional supõe que os eleitores possuem um comportamento retrospectivo e míope (expectativas adaptativas), enquanto a abordagem alternativa adota a hipótese de comportamento racional. Para a abordagem adaptativa destacam-se na literatura os trabalhos de Nordhaus (1975) e Hibbs (1977) enquanto os textos de Alesina (1987), Rogoff (1990), Person e Tabellini (1990) e Rogoff e Silbert (1998) são referências para o modelo racional.

O enfoque dado por este artigo se balizará fundamentalmente nos modelos de expectativas adaptativas propostos por Nordhaus (1975) e Hibbs (1977), assumindo-se que os eleitores no país, tendem a ter uma visão mais imediatista e de curto prazo quando avaliam os governos e os governantes e com relação às suas preferências.

O trabalho de Nordhaus (1975) assume que em períodos eleitorais os policymakers adotam políticas expansionistas a fim de influenciar a decisão dos eleitores, conquistarem os seus votos e assim permanecerem no poder. Logo após vencerem as eleições, são adotadas políticas contracionistas para reequilibrar as finanças e trazer as variáveis econômicas para níveis mais próximos do equilíbrio. Por seu turno, Hibbs (1977), apresenta um enfoque alternativo, introduzindo o componente partidário para a explicação dos motivos políticos implícitos nos ciclos 
econômicos, mantendo a perspectiva do trade-off inflação-desemprego.

Quadro 1

Tipologia dos Modelos de Viclos Político-Econômicos

\begin{tabular}{|c|c|c|c|}
\hline & & \multicolumn{2}{|c|}{ O comportamento dos eleitores é baseado em: } \\
\hline & & $\begin{array}{c}\text { Análise retrospectiva } \\
\text { (adaptativa) }\end{array}$ & $\begin{array}{l}\text { Análise prospectiva } \\
\text { (racional) }\end{array}$ \\
\hline \multirow{2}{*}{$\begin{array}{l}\text { O comportamento } \\
\text { dos políticos têm } \\
\text { motivação: }\end{array}$} & Oportunista & $\begin{array}{l}\text { Modelo tradicional } \\
\text { (Nordhaus, 1975) }\end{array}$ & $\begin{array}{c}\text { Modelo racional } \\
\text { oportunista } \\
\text { (Rogoff e Silbert, 1998; } \\
\text { Rogoff, 1990; Persson e } \\
\text { Tabellini, 1990) }\end{array}$ \\
\hline & Partidária & $\begin{array}{c}\text { Modelo tradicional } \\
\text { partidário } \\
\text { (Hibbs, 1977) }\end{array}$ & $\begin{array}{l}\text { Modelo racional } \\
\text { partidário } \\
\text { (Alesina, 1987) }\end{array}$ \\
\hline
\end{tabular}

Fonte: Adaptado de Jula e Jula (2007).

Nesse caso, porém, os partidos possuem prioridades econômicas diferentes e associadas às preferências de suas bases eleitorais, sendo os partidos de esquerda mais identificados com as classes sociais hierarquicamente mais baixas e com maior sensibilidade a problemas relacionados ao desemprego e menor à inflação, ao inverso dos partidos de direita.

\section{Modelo Oportunista Tradicional}

É consenso na literatura que o trabalho desenvolvido por Nordhaus (1975) foi o que fincou as bases do modelo oportunista tradicional de CPE. O modelo parte do pressuposto de que o comportamento dos eleitores é sensível à inflação e ao desemprego. Considera a existência de um trade-off entre o nível de inflação e o de desemprego. Justifica esse fenômeno por admitir o mercado de trabalho competitivo e o poder de negociação dos setores sindicalizados, de tal forma que uma baixa taxa de desemprego ocasiona elevação do custo da mão-de-obra. Uma segunda proposição adotada é a aceitação de que há mais trade-off no curto prazo do que no longo prazo.Uma dada mudança que provoque redução no nível do emprego, por exemplo, geraria maiores efeitos para a queda da inflação no curto prazo do que no longo prazo.

Duas razões básicas são apresentadas para justificar esta diferença: em primeiro lugar, o pressuposto habitual é que o desemprego afeta os sa-

DADOS - Revista de Ciências Sociais, Rio de Janeiro, vol. 61, nº 3, 2018 
lários e estes, em consequência, impactam os preços. Na medida em que há defasagens na relação entre desemprego e inflação, o efeito de curto prazo será menor do que o efeito a longo prazo. Em segundo lugar, há um feedback dos preços em relação aos salários. Uma inflação mais alta leva os agentes a esperar inflação também elevada no futuro. Esta taxa mais elevada de inflação esperada induz sindicatos e trabalhadores a intensificarem suas reivindicações salariais (ou seja, os trabalhadores consideram os salários reais, em vez de simplesmente salários nominais).

Assim, o modelo supõe que a economia se guia por uma Curva de Phillips aumentada pelas expectativas de inflação, em que os eleitores avaliam positivamente um maior nível de emprego e negativamente uma maior taxa de inflação, sendo que as expectativas do eleitorado em relação à inflação futura são adaptativas. Ao considerar que os eleitores, ao votarem, utilizam como parâmetro de avaliação de governo o desempenho econômico no passado recente, sendo as expectativas de inflação adaptativas, um governante oportunista buscará conduzir a política monetária de modo a induzir um ciclo de inflação-desemprego correspondente à duração do seu mandato. O candidato político oportunista não possui preferências sobre inflação e desemprego, mas se preocupa apenas com a reeleição. Sabe que os eleitores possuem memória curta e não conseguem prever efetivamente o desempenho macroeconômico futuro.

Desse conjunto de premissas resulta a existência de ciclos econômicos vinculados ao período eleitoral: o nível de atividade econômica é estimulado nos períodos mais próximos às eleições, com o consequente aumento da taxa de inflação e a redução do desemprego, seguido posteriormente por uma contração econômica gerada por políticas restritivas de caráter monetário e fiscal.

O objetivo do político é maximizar sua probabilidade de reeleição, enquanto o comportamento do eleitor é retrospectivo posto que depende do desempenho econômico passado. O desempenho econômico em um dado período $t$ é medido pelo comportamento da taxa de inflação atual $B_{t}$ e da taxa de desemprego $U_{t}$, logo a insatisfação dos eleitores pode ser representada por uma função de perda positivamente relacionada a estas duas variáveis. Podemos utilizar por simplicidade a seguinte função-perda para os eleitores conforme sugerido por Drazen (2008a): 
$\mathrm{L}\left(U_{\mathrm{t}}, \pi_{\mathrm{t}}\right)=U_{\mathrm{t}}+\theta\left(\pi_{\mathrm{t}} / 2\right)^{2}$

Tal que 2 é o peso relativo dado pelo eleitorado entre desvios da inflação e o desemprego e onde (para simplicidade de exposição) presume-se que a taxa preferencial de inflação do eleitor representativo é zero. A função-voto retrospectiva para uma eleição no final do período $t$ pode ser representada da seguinte maneira:

$V_{\mathrm{t}}=\omega\left(\sum_{n=0}^{t-1} \gamma(s) L\left(U_{\mathrm{t}-\mathrm{n}}, \pi_{\mathrm{t}-\mathrm{n}}\right)\right)$

O número de votos $V_{\mathrm{t}}$ do candidato será uma função decrescente em relação à função- perda de resultados econômicos. O comprimento exógeno de tempo entre as eleições é $T$ períodos e ( $(s)$ é peso que os eleitores dedicam a uma perda ocorrida s períodos no passado. É assumido que ( $(s)$ diminui em $s$, ou seja, quanto mais distantes no tempo passado estão os resultados econômicos, menores efeitos possuem sobre os votos no instante $t$. Se ( $(s)$ é rapidamente decrescente em $s$ os eventos muito recentes são ponderados mais fortemente pelos eleitores. No extremo, se $((s)=0$, para $s>0$, então apenas resultados econômicos ocorridos no ano da eleição afetam os votos. Poderia ser incluído na função voto algum outro elemento estocástico não determinado $\varepsilon$, para representar eventos aleatórios, choques exógenos ou preferências não captadas, de modo a permitir a possibilidade de o candidato à reeleição não ser escolhido.

Seguindo ainda em busca de ilustrar como os policy-makers manipulam as políticas econômicas, pode-se utilizar o modelo de Nordhaus que representa a estrutura da economia por uma Curva de Phillips com expectativas aumentadas relacionando a diferença entre a taxa observada $\left(U_{\mathrm{t}}\right)$ e a taxa natural de desemprego $\left(U_{\mathrm{t}}^{\mathrm{n}}\right)$ com a diferença entre a inflação atual $\left(\pi_{t}\right)$ e a esperada $\left(\pi_{t}^{e}\right)$. Fazendo uso da equação (3) para ilustrar uma Curva de Phillips:

$U_{\mathrm{t}}=U_{\mathrm{t}}^{\mathrm{n}}-\left(\pi_{\mathrm{t}}-\pi_{\mathrm{t}}^{\mathrm{e}}\right)$

Dado que os indivíduos possuem expectativas adaptativas, significa dizer que além de formar suas expectativas em relação ao valor esperado de alguma variável - como inflação e desemprego - de acordo com o resultado do período imediatamente anterior, tem essas expectativas corrigidas com base nos desvios de previsão ocorridos no passado. Assim, por exemplo, se o indivíduo acertou exatamente sua previsão passada (em t-1), não teria motivo para desconfiar que, utilizando do

DADOS - Revista de Ciências Sociais, Rio de Janeiro, vol. 61, n² 3, 2018 
princípio, não acertaria o valor presente. Ou seja, nenhum ajuste seria necessário em sua formação de expectativas. Mas se houve uma subestimação ou superestimação do valor esperado da variável, o agente terá que reconsiderar suas expectativas e ajustá-las de acordo com o tamanho do erro que cometeu.

Desse modo, podemos aceitar que um dos principais resultados do modelo é que a política inflacionária em um período eleitoral não pode ser totalmente antecipada e pode, portanto, diminuir a taxa de desemprego. Uma formulação padrão para a determinação taxa de inflação esperada é explicitada pela seguinte equação:

$\pi_{\mathrm{t}}^{\mathrm{e}}=\pi_{\mathrm{t}-1}+\beta\left(\pi_{\mathrm{t}-1}^{\mathrm{e}}-\pi_{\mathrm{t}-1}\right)$

Quando $\beta$ é um coeficiente entre 0 e 1 que representa a velocidade com a qual a inflação esperada se ajusta a erros de expectativas passadas, a equação (4) pode ser resolvida para encontrar $\pi_{t}{ }^{e}$ como uma média decrescente da soma das taxas de inflação passadas.

Pode-se resolver a equação (4) para analisar o desempenho do desemprego e a inflação ao longo do ciclo eleitoral. Quando os eleitores têm de memória curta - $(\gamma(s)$ é pequeno, para $s>0-$ a economia passa a ser conduzida em direção a um ciclo político-econômico guiado pelo governante que buscará maximizar sua probabilidade de reeleição. $\mathrm{O}$ governante oportunista, sabedor da função-perda e da inexatidão das expectativas dos eleitores, no período imediatamente seguinte à eleição provoca recessão via política monetária restritiva com a finalidade de derrubar as expectativas inflacionárias. A atividade econômica será mantida aquém do seu potencial para manter a inflação esperada baixa até o momento mais próximo às eleições. Isso permitirá que se obtenha no ano de eleição, uma taxa de expansão econômica mais elevada (induzida por um choque monetário inesperado) com uma taxa de inflação relativamente baixa. O estímulo dado via expansão monetária inesperada, possibilitará em consequência um menor desemprego no curto prazo. Ao agir deliberadamente de forma oportunista o governante consegue maximizar a satisfação do eleitor no período eleitoral. Esse processo se repete no próximo ciclo eleitoral com o governo sendo iniciado por políticas contracionistas e concluído por políticas expansionistas, seja na área monetária ou na área fiscal.

Portanto, a possibilidade de influenciar a probabilidade de reeleição, combinada com a estrutura da economia e do modo de formação de ex- 
pectativas pelos agentes, gera um ciclo na atividade econômica, que não iria estar presente com um planejador com um horizonte infinito. O ciclo político induz, assim, um ciclo na atividade econômica e inflação (Drazen, 2008a).

\section{Modelo Partidário Tradicional}

O modelo partidário formulado por Hibbs (1977) também utiliza da Curva de Phillips para explicar as oscilações no nível de emprego relacionando-as às eleições, mas diferencia a trajetória e posição na Curva de acordo com a ideologia que assumem os partidos políticos - direita ou esquerda, democratas ou trabalhistas, republicanos ou conservadores. Na verdade, ao contrário do modelo de ciclo de político oportunista, o modelo partidário afirma que os políticos maximizam funções objetivas diferentes. Tal suposição contrasta com o modelo de ciclo de político oportunista que assume os políticos como meramente oportunistas e com objetivo único da conquista / manutenção do cargo. Para chegar a essa conclusão Hibbs (1977) examinou os padrões de políticas macroeconômicas no pós-guerra e seus resultados associados às democracias capitalistas da Europa Ocidental e da América do Norte, separando-as entre aquelas governadas por partidos identificados com vieses de esquerda e de direita. Argumenta-se que os interesses econômicos objetivos, bem como as preferências subjetivas das camadas da população de baixa renda e os que exercem ocupações mais básicas no mercado de trabalho, indicam que uma baixa taxa de desemprego é preferida relativamente a uma baixa inflação, enquanto a população com renda mais elevada e os que pertencem a um grupo ocupacional com um padrão mais elevado, preferem uma taxa de desemprego maior confrontada a uma alta taxa de inflação.

Diante da diferença existente nas políticas adotadas pelos partidos, os ciclos político-econômicos irão diferir de acordo com a ideologia partidária do governante. O partido de direita tende a agradar a classe média alta, os ricos, os setores empresariais e a comunidade financeira, para isso, conduz a política econômica privilegiando o controle a baixos níveis da taxa de inflação. Por outro lado, os esquerdistas, priorizam as necessidades da classe média baixa e dos sindicatos, focando a política econômica no estímulo ao emprego. Inflação e desemprego têm consequências distributivas que ajudam a explicar essas diferenças. Ou seja, o desemprego será permanentemente menor e a inflação

DADOS - Revista de Ciências Sociais, Rio de Janeiro, vol. 61, nº 3, 2018 
maior durante administrações de partidos de esquerda em comparação com administrações de direita.

Formalmente, podemos associar a função de perda dos eleitores (1) com uma representação das preferências do partido $i$, conforme sugestão de (Drazen, 2008a):

$L^{i}\left(U_{t}, \pi_{t}\right)=\left(\mathrm{U}_{\mathrm{t}}-\mathrm{U}^{\prime j}\right)^{2} / 2+\phi^{j}\left(\pi_{t}-\pi^{\prime j}\right)^{2} / 2$

Onde $\pi^{\prime j}$ é a taxa de inflação e U'j é a taxa de desemprego que maximiza a utilidade do partido $j$ e $\phi^{j}$ é o peso que o partido $j$ confere aos desvios entre a inflação efetiva e a sua meta (preferida) relativamente a desvios do desemprego em relação ao seu nível ótimo de desemprego. Segundo o modelo partidário tradicional, os partidos de direita (DIR) e de esquerda (ESQ) são caracterizados por seguir preferências que podem ser sumarizadas como: $U^{\prime e s q}=U^{\prime d i r}, \phi^{e s q}=\phi^{d i r}$, e $\pi^{\prime e s q}=\pi^{\prime d i r}$.

Logo, os partidos com ideologia de esquerda serão mais propensos a políticas monetárias expansionistas em comparação com os partidos de direita, pois preferem um nível de emprego a uma inflação menor e mais controlada. Utilizando a mesma especificação para a relação entre desemprego e inflação em (3) e para expectativas adaptativas em (4), pode-se demonstrar que o nível de atividade econômica e de inflação está sujeito a ciclos que caminham conforme a ideologia dos partidos que dirigem os governos.

\section{Estudos Empíricos de Ciclos Político-Econômicos}

Conforme os modelos de ciclos político-econômicos evoluíram, diversos trabalhos foram formulados buscando comprovar empiricamente os aspectos propostos pela teoria. Os trabalhos têm se diferenciado não apenas pelo referencial teórico que utilizam dentre os modelos propostos em CPE, mas também em relação ao enfoque da avaliação, tendo a maior parte dos trabalhos centrado a análise em cima dos impactos nos principais indicadores econômicos tais quais: o crescimento do produto, o nível de emprego e a taxa de inflação; enquanto outra parte, mais recentemente, tem buscado observar a manipulação dos instrumentos de política econômica a exemplo de: gastos e transferências governamentais, investimentos públicos, gastos em assistência/programa social; tributação e subsídios; resultados de políticas públicas nas diversas áreas (saúde, educação, segurança). Além disso, os trabalhos diferenciam-se pelo objeto da análise podendo atingir níveis interna- 
cionais - abrangendo-se diversos países -, nacional ou mesmo no âmbito regional - estados e municípios. Diferentes métodos econométricos também têm sido utilizados: Mínimos Quadrados Ordinários, Mínimos Quadrados Generalizados, Auto Regressivo de Média Móvel (ARMA), Probit e Logit têm sido os mais comuns.

Vários trabalhos empíricos de ciclos políticos têm sido elaborados em nível de países industrializados. Entre os primeiros trabalhos constam alguns dos já citados na revisão teórica como: Nordhaus (1975), Hibbs (1977), Alesina (1987), Rogoff e Sibert (1988), Rogoff (1990), Persson e Tabellini (1990). Podemos acrescer a esta lista outros trabalhos como os de: Kramer (1971), Burdekin (1985), Pettersson-Lidbom (2000), Roth (2012), Jacobson e Kernell (1983), Jacobson (1990), Fair (1996), Gerber (1998), Grossman e Helpman (1996) e Gius (2009).

Por meio de um painel com 41 municípios da Romênia, Jula e Jula (2007), testaram a presença de CPE verificando séries de dados sobre as transferências estaduais para os orçamentos locais (municipais) e sobre o superávit orçamentário, adotando-se dummies para os anos eleitorais. Os resultados mostraram que econometricamente, existem sinais de PBC na política do orçamento em nível local, na Romênia.

Na América Latina a evidência empírica de ciclos políticos econômicos é mais limitada. Borsani (2001) analisou as eleições e o desempenho macroeconômico na região no período de 1979 e 1998. Com um painel contendo 13 países, pôde-se concluir que o crescimento do PIB em anos de eleições, seja para presidente ou em eleições exclusivamente legislativas, não apresenta variação significativa, porém, demonstra que após as eleições há uma desaceleração da atividade econômica, o que sinalizaria ao menos parcialmente a existência de ciclos políticos.

O trabalho de Larraín e Assael (1995) confirmou a existência de CPE na oferta monetária, no Produto e na política cambial para o Chile no período de 1939 a 1989. Os autores encontraram incrementos significativos na oferta monetária, na atividade econômica, e na inflação, antes das eleições.

Gámez e Ibarra-Yúnez (2009), por meio da estimação de um painel com efeitos fixos, analisou os gastos dos estados mexicanos no período de 1997 a 2004. Os resultados mostraram que os governos gastam mais no ano eleitoral e reduzem os gastos no ano seguinte à eleição.

DADOS - Revista de Ciências Sociais, Rio de Janeiro, vol. 61, n 3, 2018 
Carrillo (2012) utilizou modelos autorregressivos para analisar a existência de CPE no Equador no período de 1993 a 2010. Para tanto, verificou a reação do produto, gastos do governo, tributos e inflação dentro de cada período de governo. Os resultados encontrados indicaram maior evidência de ciclos oportunistas do que na de ciclos partidários. $\mathrm{O}$ Produto se comportou parcialmente de acordo com o que prega a Teoria de CPE, contraindo-se após as eleições no Equador.

Estudando empiricamente a existência de CPE na Colômbia, os autores López, Galló e Fresard (2002), encontraram evidências de Ciclos no Produto, na Política Monetária e nos Gastos Públicos. Constatou-se, ainda, diferença na utilização da política monetária entre os administradores liberais e conservadores.

Apesar de os modelos de CPE terem surgido e se disseminado desde a década de 1970, somente a partir da segunda metade da década de 1990 é que surgiram os primeiros trabalhos desenvolvidos para testar a aplicação daquela proposta teórica para o Brasil. O trabalho de Fialho (1996) talvez seja um dos primeiros a realizá-lo. Utilizando dados de 1953 a 1995, os resultados evidenciaram a presença de ciclo político na taxa anual de crescimento do PIB real brasileiro, bem como para a política monetária, mostrando-se que o produto e a oferta monetária são estimulados nos períodos que antecedem as eleições no Brasil.

Este resultado foi confirmado e amplificado por Salvato (2007), que encontrou evidências de que o fenômeno de Ciclos Político-Econômicos ocorreu no Brasil entre 1985 e 2006, tanto nas séries de tempo relativas aos indicadores macroeconômicos - taxa de crescimento do PIB, taxa de desemprego e taxa de inflação -, quanto nas séries ligadas aos instrumentos de política fiscal - gasto público e déficit orçamentário governamental.

Já Preussler e Portugal (2002), fizeram uso de um modelo ARIMA (Autorregressivo Integrado de Médias Móveis) para testar a presença de oportunismo político no manejo das variáveis econômicas no Brasil, analisando dados de 1980 a 2000, cujo resultado apresentou como conclusão central: que só foi detectado evidências de CPE para a taxa de inflação, descartando-se a hipótese para a taxa de desemprego e do crescimento do PIB.

Em Cossio (2001), foi feito um painel com efeitos fixos para os estados brasileiros com dados de 1985 a 1997, em que se testou a presença de ci- 
Os Ciclos Político-Econômicos e os Gastos dos Estados no Brasil: 1995-2013

clos políticos por meio das posturas fiscais. O trabalho também verificou presença de CPE, caracterizando-se as políticas fiscais dos governos estaduais por: políticas de stop and go, ou seja, anos de expansão foram seguidos por anos de contração fiscal e vice-versa; os anos eleitorais se caracterizaram pela adoção de posturas expansionistas; e, os governos estaduais usaram quase com exclusividade instrumentos de despesa tanto para adotar expansões fiscais (aumento de despesa) como para promover contrações (diminuição de despesas). Em relação à existência de diferenciação motivada por diferenças partidárias nos governos os resultados mostraram que aqueles de esquerda apresentaram um viés expansionista, não se encontrando padrões definidos para governos de direita e de centro.

Com uso de um painel dinâmico com estimador MGM, Araújo (2010) analisou os ciclos político-econômicos nos estados brasileiros no período de 1995 a 2008 e verificou comportamento oportunista por parte dos governantes do país, que elevaram os gastos públicos em anos eleitorais para em seguida realizarem ajustes nos gastos em anos póseleitorais. Em vez dos estados, Sakurai (2009) investigou a existência de ciclos eleitorais e partidários para a execução orçamentária dos municípios brasileiros de 1990 a 2005. Os resultados indicaram que o primeiro fenômeno foi observado de forma mais expressiva nas funções saúde e saneamento, habitação e urbanismo, assistência e previdência, e transportes, ao passo que, em relação aos ciclos partidários, os resultados permitiram observar a influência, ainda que parcialmente, das distinções partidárias sobre a maneira pela qual os recursos são alocados entre as funções despesas avaliadas.

O trabalho de Sakurai e Gremaud (2007) também fez uso de dados em painel para avaliar a presença de ciclos políticos orçamentários analisando-se, neste caso, a evolução das despesas e receitas dos municípios paulistas durante os governos de 1989 a 2001. Os resultados mostraram evidências de impulsos positivos na despesa municipal nos anos eleitorais de 1992 e 1996, ao passo que, no tocante às agremiações partidárias, observou-se que: PFL era o partido que mais investia; e, PTB, PPB/PDS e PMDB eram os partidos que mais despendiam recursos em transferências correntes. Foram encontradas evidências de maior volume de recursos despendidos em gastos de consumo pelas prefeituras paulistas nos anos de eleição em detrimento de uma queda nos investimentos realizados, o que, de acordo com os autores, poderia prejudicar a obtenção de um crescimento sustentado por parte dos mu-

DADOS - Revista de Ciências Sociais, Rio de Janeiro, vol. 61, n 3, 2018 
nicípios e ampliar a dependência em relação aos recursos oriundos de transferências do estado e da União.

Recentemente, alguns trabalhos têm sido realizados no Brasil para verificar se o comportamento oportunista afeta as chances eleitorais dos candidatos a prefeito e governador. Costa (2006), com base nas eleições municipais brasileiras, demonstrou que a probabilidade de reeleição de um prefeito será uma função direta da despesa do município e das transferências adicionais obtidas.

Em Sakurai e Menezes Filho (2007) foi feita uma análise via dados em painel para o período 1988-2000, também com vistas a verificar como as chances de reeleição são afetadas pela política fiscal, e constatou-se que: despesas mais elevadas efetuadas ao longo dos mandatos tendem a elevar as chances de reeleição dos prefeitos brasileiros, embora despesas mais elevadas executadas especificamente no ano eleitoral tendam a ser prejudiciais para a reeleição; os resultados indicam um elemento relevante associado a um controle por parte dos eleitores sobre um eventual comportamento oportunista por parte dos policymakers; observou-se a significância estatística e influência positiva da receita tributária e da receita de transferências correntes sobre a probabilidade de reeleição.

Alguns outros trabalhos também estudaram as chances de reeleição municipal no Brasil, restringindo a análise aos municípios de apenas um estado da Federação. Esses foram os casos de: Araújo Júnior, Cançado e Shikida (2005) para os municípios mineiros; Pereira e Fernandez (2007) para os municípios da Bahia; Queiroz e Bittencourt (2010) para o Ceará; e, Vale, Araújo e Paixão (2009) para as eleições municipais do Tocantins.

\section{METODOLOGIA E DADOS DA PESQUISA}

Para estimar as equações previstas no modelo adotado foi efetuada uma análise econométrica por meio de um painel com dados dos 26 estados brasileiros e do Distrito Federal, no período de 1995 a 2013. Aproveitando a estrutura de painel do conjunto de dados, a amostra usada consta de 513 observações. Para alcançar o objetivo de analisar o efeito do calendário eleitoral sobre variáveis fiscais estaduais não seria apropriada a utilização exclusiva de dados em corte transversal (cross section), nem de dados de séries temporais, tanto porque não se permitiria observar o impacto do tempo nas variáveis como, também, as di- 
ferenças entre distintos indivíduos da amostra (estados), além do aspecto referente a grau de liberdade. Assim para proceder à análise empírica das questões levantadas neste trabalho, foi utilizada a metodologia de dados em painel (panel data), que combina aqueles dois tipos de dados. O Teste de Hausman foi utilizado neste trabalho para a escolha do modelo mais eficiente e consistente.

Segundo Wooldridge (2014), o uso de dados em painel apresenta algumas vantagens em relação aos dados de corte transversal ou de cortes transversais agrupados destacando-se o controle de certas características não observáveis dos indivíduos, possibilitadas pela observação múltipla ao longo do tempo. No caso do objeto deste estudo é lógico considerar que cada estado possui características particulares que os diferenciam e influenciam na forma como são escolhidos os seus governantes, bem como, no modo como são destinados os recursos públicos. Estas características afetam a variável que se pretenda explicar, mas não são possíveis de serem plenamente mensuradas. A omissão dessas variáveis que representam determinadas características diferenciadoras das distintas unidades (estados) poderia gerar resultados viesados. Porém, o uso de modelos de dados em painel permite controlar essas diferenças e obter estimadores consistentes e não viesados.

Para a estimação do modelo são utilizados três tipos de dados: instrumentos de política fiscal, neste caso o gasto público considerando-se as diferentes categorias econômicas e de elemento de despesa orçamentária, que serão assumidas como variáveis explicativas; variáveis de controle e variáveis políticas, que são dummies definidas para os anos do mandato, bem como, para os diferentes partidos. Os dados foram coletados a partir de fontes secundárias, sobretudo o sítio da Secretaria do Tesouro Nacional (STN) no qual estão disponibilizados os dados de execução orçamentária dos estados. Quanto às variáveis políticas, foram coletados os dados disponíveis no TSE (Tribunal Superior Eleitoral) e nos Tribunais Regionais Eleitorais (TREs). O modelo a ser estimado seguirá padrões semelhantes ao executado por Gámez e Ibarra-Yúnez (2009), cuja análise é feita por meio de Painel com efeitos fixos ou variáveis. O modelo básico utilizado para estimar as regressões apresentará a seguinte especificação geral:

$\mathrm{Yi}, \mathrm{t}=\Sigma b k \mathrm{Fi}, \mathrm{t}-\mathrm{k}+\Sigma c \mathrm{Xi}, \mathrm{t}+d \mathrm{ELEC} \mathrm{t}+\mathrm{Mi}+\mathrm{Ei}, \mathrm{t}$

Onde: 
$Y i, t=$ Indicador fiscal do Estado i no tempo $t$

$\mathrm{X} \mathrm{i}, \mathrm{t}=$ Vetor de variáveis de Controle

ELECt $=$ Dummy eleitorais

$\mathrm{Mi}=$ Efeito fixo por estado

$\mathrm{Ei}, \mathrm{t}=$ componente de erro

A estimação foi realizada utilizando-se as seguintes variáveis dependentes de gasto: (i) despesa total; (ii) despesas correntes; (iii) despesas de capital; (iv) investimentos; (v) pessoal e encargos sociais; (vi) habitação e urbanismo; (xii) transportes; (viii) educação; (ix) obras e instalações; e (x) urbanismo.

Todas estas variáveis foram deflacionadas* para posteriormente serem calculadas as taxas de variação anual real dos gastos no período estudado, com uso de transformação logarítmica.

O Quadro 2 descreve as variáveis políticas e regionais utilizadas e mostra os sinais esperados dos efeitos dessas variáveis explicativas sobre o comportamento fiscal dos estados brasileiros.

Para as variáveis independentes que representam os ciclos políticos orçamentários, foram definidas três dummies para identificar e representar o ciclo eleitoral para eleições governamentais: DAE $=1$ no ano pré-eleitoral e 0 , caso contrário; $\mathrm{DDE}=1$ se ano pós-eleitoral e 0 caso contrário; $\mathrm{DDDE}=1$ se é o segundo ano após a eleição e 0 , caso contrário. Utiliza-se neste caso, os anos eleitorais (DE) como dummy de referência ou comparação de modo que receberá o valor 0 (zero), enquanto as demais variáveis qualitativas que representam o ciclo eleitoral recebem o valor 1 (um).

Ainda quanto às variáveis políticas, foi criada a dummy CREELE que assumirá o valor 1 caso o governante esteja concorrendo à reeleição, e 0 , caso contrário. Mais uma vez, espera-se que o fato de o próprio governante estar concorrendo à renovação do mandato estimulará o oportunismo eleitoral e, portanto, o aumento dos gastos no ano eleitoral.

No que se refere às variáveis de controle foi utilizada a Receita Total cujos valores, assim como as variáveis de despesa, foram deflacionados para posteriormente serem calculadas as taxas de variação anual

* Os dados foram deflacionados pelo IPCA (índice de Preços ao Consumidor Amplo) do IBGE (Instituto Brasileiro de Geografia e Estatística), utilizando-se o ano de 1995 como ano-base. 
Os Ciclos Político-Econômicos e os Gastos dos Estados no Brasil: 1995-2013

Quadro 2

Variáveis Explicativas do Comportamento Fiscal dos Estados

\begin{tabular}{|c|c|c|}
\hline $\begin{array}{c}\text { Variável } \\
\text { Explicativa }\end{array}$ & Descrição & $\begin{array}{c}\text { Sinal } \\
\text { Esperado }\end{array}$ \\
\hline DAE & $\begin{array}{l}\text { Ano pré-eleitoral para Governador/ Dummy igual a } 1 \text { se } \\
\text { ano pré-eleitoral e } 0 \text {, caso contrário }\end{array}$ & - \\
\hline DDE & $\begin{array}{l}\text { Ano pós-eleitoral para Governador / Dummy igual a } 1 \text { se } \\
\text { ano pós-eleitoral e } 0 \text {, caso contrário }\end{array}$ & - \\
\hline DDDE & $\begin{array}{c}\text { Dois anos após a eleição para Governador / Dummy } \\
\text { igual a } 1 \text { se segundo ano pós-eleitoral e } 0 \text {, em caso } \\
\text { contrário }\end{array}$ & - \\
\hline CREELE & $\begin{array}{c}\text { Candidato à reeleição / Dummy }=1 \text { se candidato à } \\
\text { reeleição e } 0, \text { caso contrário }\end{array}$ & + \\
\hline ESQ & $\begin{array}{c}\text { Partido de Esquerda / Dummy }=1 \text { se o partido for de } \\
\text { Esquerda, 0, se outro caso }\end{array}$ & + \\
\hline DIR & $\begin{array}{c}\text { Partido de Direita / Dummy }=1 \text { se o partido for de } \\
\text { Direita, } 0 \text { se outro caso }\end{array}$ & - \\
\hline CENT & $\begin{array}{l}\text { Partido de Centro/ Dummy }=1 \text { se o partido for de } \\
\text { Centro, } 0 \text { se outro caso }\end{array}$ & - \\
\hline RECTOT & Log da receita total real & + \\
\hline ELEIT & Log índice do número de eleitores & + \\
\hline
\end{tabular}

Fonte: Elaboração própria.

real, com uso de transformação logarítmica - e o número de eleitores também transformado em taxa mediante transformação logarítmica. Assume-se que as despesas orçamentárias são feitas levando em consideração as receitas auferidas no período. Quanto ao número de eleitores, dado que supomos que os governantes desejam maximizar votos, espera-se que quanto maior o número de eleitores, maior deverá ser o volume de gastos. Assim, espera-se uma relação positiva dos gastos com as variáveis de controle.

Adotou-se as variáveis dummies ESQ, DIR e CENT para representar os governos com partidos de esquerda, direita e centro com o intuito de capturar possíveis diferenças no volume de gastos dos diferentes partidos enquanto governam os estados brasileiros, ao longo de todo o mandato. De um modo geral, espera-se que, no agregado, os partidos de esquerda apresentem maior volume de gastos que aqueles com diferentes perfis ideológicos; e que essa distinção nos gastos seja mais expressiva nas funções de despesa relacionadas a gastos sociais como habitação, pessoal e encargos sociais e educação. Foram utilizados, neste caso, os partidos de esquerda como dummy de referência ou comparação de modo que receberá o valor 0 (zero), enquanto os partidos de centro e de direita receberão o valor 1 (um).

DADOS - Revista de Ciências Sociais, Rio de Janeiro, vol. 61, n 3, 2018 
Daniel Guerra, Adriano Nascimento da Paixão e Paulo Amilton Maia Leite Filho

\section{Classificações dos Partidos Políticos no Brasil}

Cumprindo a finalidade de identificar se as diferenças partidárias provocam algum efeito no comportamento das categorias de despesas a serem analisadas, são inseridas dummies para três categorias ideológico-partidárias assumidas neste trabalho: direita, esquerda e centro. Essa opção segue proposta semelhante àquelas utilizadas por Cossio (1998), Bittencourt (2002), Nakaguma (2006) e Araújo (2010), cujos trabalhos classificaram os partidos políticos dentre os três espectros ideológicos citados. A classificação dos partidos dentre as três categorias foi feita com base nos trabalhos de Tarouco e Madeira (2013) e Rodrigues (2002b), que a partir dos conteúdos programáticos dos partidos brasileiros e sua vinculação a temas mais ligados à esquerda ou direita, bem como das diferenças na composição social das respectivas bancadas partidárias, classificaram os partidos dentre as três categorias distintas. Foram definidos então como partidos de direita: PFL (DEM), PL, PSD, PSC, PSL, PPB, PPR, PP; como partidos de centro: PMDB, PSDB, PTB; e, como partidos de esquerda: PT, PDT, PSB, PPS, $P V, P M N$ e PC do B.

Essa classificação também é bastante próxima daquelas apresentadas em Coppedge (1997) e em Power e Zucco (2008), embora tenham sido formadas por métodos distintos. O primeiro consultou 53 especialistas em ciência política acerca das características e afinidades dos partidos latino-americanos com temas vinculados às dimensões ideológicas compreendidas entre a esquerda e a direita, de modo a classificar os partidos com perfis semelhantes entre os grupos que passam da esquerda - que teriam, por exemplo, maior preocupação com justiça, igualdade e mobilidade social - atravessa o centro - partidos que não possuem uma agenda social ou econômica determinada ou orientada até a direita - formada por partidos com discurso moralizante, que pregam a ordem pública, enfatizam a iniciativa privada e o crescimento em relação à distribuição de renda -, tendo, ainda, subdividido os grupos entre os partidos de centro-esquerda e centro-direita, e até mesmo em partidos ditos personalistas - identificados na figura de um líder político. No caso brasileiro, foi tomada como base a composição das Assembleias Nacionais nos anos de 1945 a 1994, tendo-se identificado para os períodos mais recentes - última década da amostra, por exemplo, o PT (Partido dos Trabalhadores) e o PC do B (Partido Comunista do Brasil) como partidos de esquerda, o PMDB (Partido do Movimento Democrático Brasileiro), como de Centro e PP (Partido Progressista) e PSD (Partido Social Democrático), como partidos de direita. Já 
Power e Zucco (2008), a partir das respostas aos questionários de pesquisa aplicados em cerca de 850 legisladores federais do período de 1990 a 2005, desenvolveu uma escala ideológica dos partidos brasileiros, situando-os entre aqueles identificados como de esquerda ou de direita, cujos resultados também colocam o PT e o PC do B como partidos ideologicamente de esquerda, por exemplo.

Em Rodrigues (2002a) são citados fatores que vêm sendo apontados por cientistas políticos que têm estudado o sistema político para indicar um quadro de instabilidade e inconsistência partidária no Brasil: 1) a alta fragmentação partidária decorrente do excessivo número de partidos; 2) fragilidade dos partidos manifestada pela baixa longevidade; 3) alta taxa de migração partidária pelos políticos, aspecto que se vincula à falta de coesão, disciplina e fidelidade partidária; 4) inconsistência ideológico-programática, explicitada pelas incongruentes coligações eleitorais; 5) cultura da patronagem, clientelismo e patrimonialismo ainda presente e alimentada na sociedade. Contudo, o autor argumenta que a direção das mudanças parece indicar o fortalecimento dos partidos, tanto no que se refere à configuração de seu perfil ideológico e capacidade de expressar demandas da sociedade, como no que se refere à sua capacidade de dar sustentação partidária aos governos. Sugere ainda que, o levantamento da composição ocupacional das bancadas indica diferenças significativas entre os partidos, singularizando-os e fazendo com que suas cúpulas representem interesses socioeconômicos diferenciados, relativamente compatíveis com as posições políticas assumidas pelos seus representantes.

A elaboração do modelo partidário para a Teoria dos Ciclos Político-Econômicos, tal qual feitas em Hibbs (1977), Alesina (1987) e Alesina, Roubini e Cohen (1997), encontraram efeitos partidários nos resultados macroeconômicos dos países. Porém, tais efeitos foram identificados para economias que possuem sistemas políticos bipartidarizados ou concentrados em poucos partidos, com histórico democrático ampliado e níveis de renda e educacionais elevados, em comparação com o Brasil.

A aparente inconsistência ideológica dos partidos brasileiros será testada no modelo especificado em (08), através de estimação econométrica, cujos resultados são apresentados na seção seguinte. Caso não haja distinção nas preferências e modelos de gestão dos partidos brasileiros no tocante às áreas em que são aplicados os gastos públicos, os testes estatísticos o demonstrarão. 


\section{APRESENTAÇÃO E ANÁLISE DOS RESULTADOS DAS ESTIMAÇÕES}

A Tabela 1 apresenta os resultados das estimações para as variáveis dependentes Despesa Total, Despesas Correntes, Despesas de Capital e Investimento. Nas colunas (1) e (2) temos os modelos para a Despesa Total e Despesas Correntes, enquanto nas colunas (3) e (4) seguem os modelos para as Despesas de Capital e de Investimento, respectivamente.

Tabela 1

Estimações para a Despesa Total, Despesas Correntes, Despesas de Capital e Investimentos dos Estados -(1995/2013)

\begin{tabular}{|c|c|c|c|c|}
\hline & Despesa Total & $\begin{array}{l}\text { Despesas } \\
\text { Correntes }\end{array}$ & $\begin{array}{c}\text { Despesas de } \\
\text { Capital }\end{array}$ & Investimentos \\
\hline \multirow[t]{2}{*}{ Variáveis/Modelos } & EA & EF & EA & EA \\
\hline & (1) & (2) & (3) & (4) \\
\hline \multirow[t]{2}{*}{ lrectot } & 0,89868 & 0,84957 & 0,91587 & 0,78933 \\
\hline & $(0,000)$ & $(0,000)$ & $(0,000)$ & $(0,000)$ \\
\hline \multirow{2}{*}{ dae } & $-0,01807$ & $-0,02246$ & $-0,01634$ & $-0,03736$ \\
\hline & $(0,001)$ & $(0,000)$ & $(0,415)$ & $(0,081)$ \\
\hline \multirow[t]{2}{*}{ dde } & $-0,00656$ & 0,00310 & $-0,08419$ & $-0,16141$ \\
\hline & $(0,489)$ & $(0,766)$ & $(0,000)$ & $(0,000)$ \\
\hline \multirow[t]{2}{*}{ ddde } & $-0,01124$ & $-0,00641$ & $-0,03562$ & $-0,08094$ \\
\hline & $(0,153)$ & $(0,463)$ & $(0,064)$ & $(0,000)$ \\
\hline \multirow[t]{2}{*}{ leleit } & 0,02192 & $-0,10265$ & 0,99321 & 1,07452 \\
\hline & $(0,925)$ & $(0,696)$ & $(0,086)$ & $(0,173)$ \\
\hline \multirow[t]{2}{*}{ tend } & 0,00013 & 0,00480 & $-0,01886$ & $-0,016277$ \\
\hline & $(0,28)$ & $(0,214)$ & $(0,002)$ & $(0,103)$ \\
\hline \multirow[t]{2}{*}{ cent } & $-0,00202$ & $-0,00221$ & 0,00364 & $-0,05368$ \\
\hline & $(0,736)$ & $(0,744)$ & $(0,908)$ & $(0,207)$ \\
\hline \multirow[t]{2}{*}{ dir } & $-0,01780$ & $-0,03057$ & $-0,01144$ & $-0,07955$ \\
\hline & $(0,071)$ & $(0,026)$ & $(0,701)$ & $(0,151)$ \\
\hline \multirow[t]{2}{*}{ creele } & 0,00777 & $-0,00861$ & 0,0656 & 0,08029 \\
\hline & $(0,299)$ & $(0,338)$ & $(0,063)$ & $(0,058)$ \\
\hline \multirow[t]{2}{*}{ const } & 0,15497 & $-0,00861$ & $-1,70921$ & $-1,47208$ \\
\hline & $(0,764)$ & $(0,338)$ & $(0,133)$ & $(0,351)$ \\
\hline $\mathrm{N}^{0}$ de observações & 513 & 513 & 513 & 513 \\
\hline $\mathbf{r}^{2}$ within & 0,9274 & 0,9039 & 0,5767 & 0,4162 \\
\hline
\end{tabular}


Os Ciclos Político-Econômicos e os Gastos dos Estados no Brasil: 1995-2013

Tabela 1

Estimações para a Despesa Total, Despesas Correntes, Despesas de Capital e

\begin{tabular}{ccccc} 
& Investimentos dos Estados -(1995/2013) & (continuação) \\
\hline & Despesa Total & $\begin{array}{c}\text { Despesas } \\
\text { Correntes }\end{array}$ & $\begin{array}{c}\text { Despesas de } \\
\text { Capital }\end{array}$ & Investimentos \\
\hline $\mathbf{r}^{2}$ between & 0,8422 & 0,7823 & 0,216 & 0,0222 \\
\hline $\mathbf{r}^{2}$ overall & 0,9137 & 0,8857 & 0,4358 & 0,2462 \\
\hline Estatística F & & 551,67 & \\
\hline P>F (p-valor) & & $(0,00)$ & 318,92 \\
\hline Wald & 12329,34 & & 277,37 & 0,00 \\
\hline Wald P>chi2 & $(0,00)$ & 0,00 & 1,47 \\
\hline Teste de Hausman & 7,07 & 21,67 & 2,73 & $(0,997)$ \\
\hline
\end{tabular}

Fonte: Elaborado pelo autor a partir de resultados do trabalho, utilizando-se o software Stata 12 para a estimação da regressão dos dados. Notas: Os p-valores estão entre parênteses. Os parâmetros que apresentaram significância estatística estão em negrito.

Os modelos são identificados por EA quando estimados por efeitos aleatórios e EF quando por efeitos fixos, EAA e EFA, quando o modelo for ampliado pela inclusão de variáveis políticas.

O modelo para Despesa Total sugere a presença de ciclos políticos na execução dos gastos, embora em percentuais relativamente baixos. No ano imediatamente anterior à eleição (DAE), os gastos são cerca de $1,80 \%$ inferiores enquanto no segundo ano após a eleição (DDDE) os gastos totais tendem a reduzir cerca de $1,12 \%$ em termos reais, mas não apresenta significância estatística - p-valor 15\% - enquanto a variável dummy que representa o ano pós-eleitoral (DDE) não se mostrou significativa, embora tenha registrado sinal negativo, de acordo com o esperado na teoria. Por outro lado, a variável partidária (DIR), que ilustra a dummy para os partidos de ideologia de direita, apresenta-se significativa indicando que esses partidos gastam $1,78 \%$ menos ao longo de seus mandatos do que aqueles partidos com ideologia de esquerda.

A estimação para despesas correntes, sob a qual se incluem as despesas de custeio - pessoal, consumo, serviços de terceiros - e as transferências correntes dos estados, apresentou resultado próximo àquele encontrado para aquela com uso da variável dependente Despesa Total. No modelo estimado (2) a variável (DAE) apresentou significância estatística, indicando que nos anos anteriores à eleição, os gastos correntes são cerca de $1,24 \%$ inferiores. As demais variáveis que representam o ciclo político orçamentário não se mostraram significantes estatisticamente. Aqui, novamente a variável partidária (DIR) apresenta-se 
significativa, indicando que esses partidos gastam 3,00\% menos em Despesas Correntes ao longo de seus mandatos que os partidos com ideologia de esquerda.

O fato de haver um comportamento bastante aproximado na realização dos gastos enquadrados como Despesas Totais e Despesas Correntes se justifica pelas seguintes razões: as despesas correntes compreendem grande parte das despesas totais - no geral, a maioria dos estados gasta próximo do limite máximo permitido com despesas de pessoal, que, por sua vez, corresponde à maior parte dos gastos em Despesas Correntes; os gastos com pessoal possuem limitações legais que impedem sua livre flutuação a mero desejo ou discricionariedade do gestor; imposições legais também comprometem grande parcela do orçamento com gastos em saúde - mínimo de $12 \%$ da arrecadação dos impostos de base estadual - e com educação - mínimo de $25 \%$ da receita resultante dos impostos -, que, somados às despesas com outras funções sociais relevantes, como segurança pública, saneamento, assistência social e repasses de duodécimos para o Poder Judiciário, Ministério Público, Tribunal de Contas e Assembleia Legislativa, tornam os orçamentos estaduais engessados e fortemente vinculados, restringindo a margem de discricionariedade dos gastos.

O modelo (3) para Despesas de Capital-compostas por investimentos, inversões financeiras, transferências e amortizações de dívidas - sugere forte presença de ciclos políticos na execução dos gastos. As estimações indicam queda de 1,63\% - não estatisticamente significante -, $8,41 \%$ e $3,56 \%$, para as variáveis (DAE), (DDE) e (DDDE), respectivamente. Além disso, verifica-se uma tendência a uma queda nos gastos com Despesas de Capital ao longo do tempo. Para as variáveis políticas encontra que os governantes que concorrem à reeleição gastam $6,56 \% \mathrm{a}$ mais nos anos eleitorais do que aqueles que não disputam a reeleição. As variáveis partidárias, contudo, não mostraram significância estatística, indicando que não há diferença substantiva entre os partidos em relação à execução de gastos com esse tipo de despesa, ou seja, as diferentes correntes ideológicas agem de maneira oportunista e tendem a expandir as Despesas de Capital em anos eleitorais de modo semelhante.

A estimação (4) para as despesas de investimento - que incluem obras e instalações, equipamentos e material permanente, constituição ou aumento do Capital de Empresas - constata uma presença forte de ciclos 
políticos orçamentários. Os resultados mostram que em anos anteriores à eleição (DAE) investe-se 3,73\% menos do que nos anos eleitorais, enquanto essa queda é ainda maior para os anos pós-eleitorais (DDE), sendo inferior em 16,14\%, - em 8,09\% para os anos seguintes às eleições (DDDE).

Quanto às variáveis políticas, têm-se que os gastos dos governantes candidatos à reeleição são $8,0 \%$ superiores àqueles que não concorrem a um novo mandato. Da mesma forma do que foi verificado nas estimações para a variável Despesas de Capital, também não foi demonstrada, estatisticamente, diferença no padrão de gastos em investimentos dos governantes estaduais que sejam motivadas por razões ideológicas.

A Tabela 2 mostra os resultados das estimações para as Despesas de Pessoal e de Habitação e Urbanismo - que incluem habitação urbana e rural, infra-estrutura urbana, serviços urbanos e transportes coletivos urbanos -, Transportes - sob as quais se incluem o transporte rodoviário, ferroviário, hidroviário e aéreo - e Educação - que englobam gastos com ensino fundamental, médio, profissional, superior, educação infantil, educação de jovens e adultos, educação especial e demais subfunções.

Para as despesas com pessoal, verifica-se a presença de efeitos do calendário eleitoral na condução fiscal dos estados cujo comportamento indica o comportamento de ciclos políticos econômicos oportunistas.

No modelo (1) para despesas com pessoal, os resultados sugerem que há uma queda nos gastos com pessoal em termos reais, de $4,71 \%$ no ano anterior à eleição (DAE), e uma redução de 2,30\% no segundo ano após a eleição (DDDE). A variável (DDE) indica que no ano imediatamente após a eleição os gastos com pessoal seriam ligeiramente majorados, comparativamente, em cerca de $1,28 \%$, tendo contudo registrado fraca significância estatística.

O fato da dummy DDE sugerir uma elevação nas despesas com pessoal em anos pós-eleitorais, poderia ser explicado pelo forte caráter inercial desse tipo de despesa, já que direitos trabalhistas impedem a redução em salários, além disso, promessas de campanha, possíveis acordos com sindicatos e com categorias de servidores públicos por melhores planos de carreira e remuneração, teriam impacto não somente em anos eleitorais, mas ainda em anos seguintes. Já as demais variáveis de natureza político-ideológica não tiveram resultados estatisticamente significantes. 
Daniel Guerra, Adriano Nascimento da Paixão e Paulo Amilton Maia Leite Filho

Tabela 2

Estimações para a Despesa de Pessoal, Habitação e Urbanismo, Transportes e Educação dos Estados - (1995/2013)

\begin{tabular}{|c|c|c|c|c|}
\hline & Pessoal & $\begin{array}{l}\text { Habitação e } \\
\text { Urbanismo }\end{array}$ & Transportes & Educação \\
\hline \multirow[t]{2}{*}{ Variáveis/Modelos } & $\mathrm{EF}$ & EA & EA & EA \\
\hline & (1) & $(2)$ & (3) & (4) \\
\hline \multirow[t]{2}{*}{ lrectot } & 0,85085 & 0,69032 & 0,32959 & 0,81222 \\
\hline & $(0,000)$ & $(0,000)$ & $(0,020)$ & $(0,000)$ \\
\hline \multirow[t]{2}{*}{ dae } & $-0,04716$ & $-0,05193$ & $-0,03809$ & $-0,04831$ \\
\hline & $(0,000)$ & $(0,271)$ & $(0,255)$ & $(0,000)$ \\
\hline \multirow[t]{2}{*}{ dde } & 0,01289 & $-0,14295$ & $-0,12449$ & $-0,015550$ \\
\hline & $(0,250)$ & $(0,000)$ & $(0,000)$ & $(0,499)$ \\
\hline \multirow[t]{2}{*}{ ddde } & $-0,02305$ & $-0,02852$ & $-0,09192$ & $-0,03714$ \\
\hline & $(0,045)$ & $(0,614)$ & $(0,008)$ & $(0,055)$ \\
\hline \multirow[t]{2}{*}{ leleit } & 0,26846 & 0,87967 & 0,02152 & 0,05185 \\
\hline & $(0,655)$ & $(0,425)$ & $(0,984)$ & $(0,825)$ \\
\hline \multirow[t]{2}{*}{ tend } & 0,00169 & 0,01721 & 0,01799 & $-0,00271$ \\
\hline & $(0,804)$ & $(0,300)$ & $(0,238)$ & $(0,520)$ \\
\hline \multirow[t]{2}{*}{ cent } & $-0,01274$ & $-0,03858$ & $-0,06982$ & $-0,05040$ \\
\hline & $(0,506)$ & $(0,670)$ & $(0,098)$ & $(0,020)$ \\
\hline \multirow[t]{2}{*}{ dir } & $-0,04266$ & $-0,09397$ & $-0,06913$ & $-0,029141$ \\
\hline & $(0,179)$ & $(0,268)$ & $(0,222)$ & $(0,208)$ \\
\hline \multirow[t]{2}{*}{ creele } & $-0,01639$ & 0,0189 & 0,00093 & $-0,03164$ \\
\hline & $(0,265)$ & $(0,746)$ & $(0,985)$ & $(0,019)$ \\
\hline \multirow[t]{2}{*}{ const } & $-0,29332$ & $-1,21727$ & 1,35752 & 1,35752 \\
\hline & $(0,812)$ & $(0,567)$ & $(0,525)$ & $(0,525)$ \\
\hline № de observações & 513 & 508 & 509 & 511 \\
\hline $\mathbf{r}^{2}$ within & 0,7909 & 0,338 & 0,2513 & 0,5336 \\
\hline $\mathbf{r}^{2}$ between & 0,258 & 0,040 & 0,1023 & 0,434 \\
\hline $\mathbf{r}^{2}$ overall & 0,656 & 0,205 & 0,1629 & 0,518 \\
\hline Wald & & & 105,21 & 1624,08 \\
\hline Wald P>chi2 & & & 0,00 & 0,00 \\
\hline \multirow[t]{2}{*}{ Teste de Hausman } & 60,2 & 151,39 & 1,33 & 2,04 \\
\hline & 0,00 & 0,00 & $(0,998)$ & $(0,9908)$ \\
\hline
\end{tabular}

Fonte: Elaborado pelo autor a partir de resultados do trabalho, utilizando-se o software Stata 12 para a estimação da regressão dos dados. Notas: Os p-valores estão entre parênteses. Os parâmetros que apresentaram significância estatística estão em negrito.

Os modelos são identificados por EA quando estimados por efeitos aleatórios e EF quando por efeitos fixos. 
O efeito reduzido, embora presente, do período eleitoral na variação das despesas com pessoal, em comparação com outras funções de despesas como aquelas efetuadas com Investimento e Habitação, pode ter como causa as limitações e controle decorrentes da aplicação da Lei Complementar no 101/2000, mais conhecida como Lei de Responsabilidade Fiscal (LRF), e da própria Constituição Federal.

A LRF, além de fixar um teto para as despesas totais com pessoal dos estados em $50 \%$ da Receita Corrente Líquida, impõe sanções na forma de impedimentos no recebimento de transferências voluntárias, na obtenção de garantias de outro ente ou na contratação de créditos. Além disso, a referida Lei torna nulo qualquer aumento de despesa com pessoal expedido nos 180 (cento e oitenta) dias anteriores ao final dos mandatos dos titulares dos Poderes ou órgãos, incluindo-se o chefe do Poder Executivo estadual. Portanto, o advento da Lei de Responsabilidade Fiscal limitou a autonomia dos governantes em manusear de forma oportunista as despesas com pessoal, que pudesse ser encetada seja pela majoração de salários e benefícios remuneratórios, seja através da contratação de novos servidores. Quanto a este último ponto, a própria Constituição Federal de 1988, também limita a possibilidade de contratação de pessoal ao estabelecer e exigência de submissão a concurso público para a investidura em cargo ou emprego público.

No caso das estimações para Despesas com Habitação e Urbanismo (2), a única variável, além do controle LRECTOT, que apresentou significância estatística, foi a dummy (DDE), indicando forte queda nesta função de despesa em anos pós-eleitorais, em percentuais superiores a $14 \%$. As demais variáveis que representam o ciclo orçamentário, embora tenham registrado sinais negativos em seus coeficientes no percentual de $5,19 \%$ e $2,85 \%$ consoante esperado pela teoria, estes apresentaram baixa significância estatística.

O modelo (3), para os gastos com transporte, indica importante comportamento oportunista. Os gastos nos dois anos seguintes ao ano eleitoral apresentam quedas de cerca de $12,44 \%$ para o primeiro ano (DDE) e de $9,20 \%$ para o ano seguinte (DDDE). A dummy (DAE) também apresentou parâmetro com sinal negativo, mas sem significância estatística. Observando o efeito do caráter partidário no padrão dos gastos com transporte, constatou-se que os partidos enquadrados como sendo de centro, tendem a gastar aproximadamente $7,0 \%$ menos em transportes ao longo de seus mandatos que os partidos definidos como sendo de esquerda. 
A estimação para as despesas com educação constante na coluna (4) da tabela 2 encontrou sinais de efeitos oportunistas e cíclicos. Os resultados mostram que os gastos feitos nos anos anteriores à eleição são $4,83 \%$ inferiores ao ano eleitoral. Além disso, no período intermediário (DDDE), haveria uma queda de $3,71 \%$ nos gastos reais em comparação com o ano eleitoral.

O comportamento oportunista é ainda constatado para os políticos que concorrem à reeleição que, em geral gastam 3,16\% menos em educação nos anos de eleição. O oportunismo, neste caso, poderia ser explicado pelo fato de que a educação possui importante componente de subjetividade e, de um modo geral, requer prazos mais elásticos para alcançar resultados em termos de qualidade, de modo que, a ampliação dos gastos com educação em anos de eleição - notadamente aqueles que não se referem à construção e reforma de instalações - não oferecem visualmente, à maior parte dos eleitores, apelo impactante que possa indicar competência do governante. Os resultados sugerem ainda que o viés ideológico-partidário também afeta os gastos em educação, sendo que os partidos de centro gastam cerca de 5,0\% menos em educação ao longo de seus mandatos do que os partidos de esquerda.

Quando comparadas aos gastos com transportes ou gastos com investimentos, as despesas com educação revelam um comportamento menos instável e com menor influência do calendário político-eleitoral, apesar da identificação do ciclo oportunista em suas trajetórias. Além do fato de aparentemente possuírem um menor apelo eleitoral, o menor efeito dos ciclos políticos sobre a evolução dos gastos com educação é resultado de regramentos legais que impedem a redução de gastos e vinculam fontes de receitas dos estados às despesas com educação.

A Constituição Federal exige dos estados e municípios a aplicação anual nunca inferior a $25 \%$, da receita resultante dos impostos na manutenção e desenvolvimento do ensino. Por si só, tal imposição Constitucional limita a discricionariedade do governante nos gastos com educação ao estabelecer um piso que corresponde a grande fração de suas receitas.

Além disso, uma substantiva parcela de recursos aplicados em educação pelos estados são provenientes de transferências recebidas da União por meio do Fundo Nacional de Desenvolvimento da Educação (FNDE) com destinações específicas vinculadas a programas como o Programa Nacional de Alimentação Escolar (PNAE), o Programa Dinheiro Direto na Escola (PDDE) e o Programa de Apoio a Estados e Municípios para a Educação Fundamental de Jovens e Adultos (EJA). 
Os Ciclos Político-Econômicos e os Gastos dos Estados no Brasil: 1995-2013

Tabela 3

Estimações para as Despesas com Obras e Urbanismo dos Estados — (2002/2013)

\begin{tabular}{|c|c|c|}
\hline & Obras & Urbanismo \\
\hline \multirow[t]{2}{*}{ Variáveis/Modelos } & EA & EA \\
\hline & (1) & $(2)$ \\
\hline \multirow[t]{2}{*}{ lrectot } & 0,38033 & 0,16715 \\
\hline & $(0,004)$ & $(0,371)$ \\
\hline \multirow[t]{2}{*}{ dae } & $-0,07000$ & $-0,19430$ \\
\hline & $(0,018)$ & $(0,019)$ \\
\hline \multirow[t]{2}{*}{ dde } & $-0,18433$ & $-0,22132$ \\
\hline & $(0,000)$ & $(0,007)$ \\
\hline \multirow[t]{2}{*}{ ddde } & $-0,14518$ & $-0,16565$ \\
\hline & $(0,000)$ & $(0,063)$ \\
\hline \multirow[t]{2}{*}{ leleit } & 0,20293 & $-0,39740$ \\
\hline & $(0,843)$ & $(0,852)$ \\
\hline \multirow[t]{2}{*}{ tend } & 0,02369 & 0,05034 \\
\hline & $(0,024)$ & $(0,200)$ \\
\hline \multirow[t]{2}{*}{ cent } & 0,01128 & $-0,15641$ \\
\hline & $(0,777)$ & $(0,221)$ \\
\hline \multirow[t]{2}{*}{ dir } & $-0,01374$ & $-0,02345$ \\
\hline & $(0,800)$ & $(0,865)$ \\
\hline \multirow[t]{2}{*}{ creele } & 0,0392 & $-0,05752$ \\
\hline & $(0,321)$ & $(0,736)$ \\
\hline \multirow[t]{2}{*}{ const } & 0,68777 & 2,51594 \\
\hline & $(0,726)$ & $(0,564)$ \\
\hline $\mathrm{N}^{0}$ de observações & 324 & 294 \\
\hline $\mathbf{r}^{2}$ within & 0,4674 & 0,1232 \\
\hline$r^{2}$ between & 0,0156 & 0,1282 \\
\hline $\mathbf{r}^{2}$ overall & 0,2316 & 0,0940 \\
\hline Wald & 151,34 & 40,65 \\
\hline Wald P>chi2 & 0,00 & 0,00 \\
\hline \multirow[t]{2}{*}{ Teste de Hausman } & 12,41 & 3,93 \\
\hline & $(0,191)$ & $(0,916)$ \\
\hline
\end{tabular}

Fonte: Elaborado pelo autor a partir de resultados do trabalho, utilizando-se o software Stata 12 para a estimação da regressão dos dados. Notas: Os p-valores estão entre parênteses. Os parâmetros que apresentaram significância estatística estão em negrito.

Os modelos são identificados por EA quando estimados por efeitos aleatórios e EF quando por efeitos fixos.

A Tabela 3 exibe os resultados das estimações para as Despesas com Obras e Instalações e com Urbanismo - esta agora desagregada da função habitação - para o período de 2002 a 2013.

DADOS - Revista de Ciências Sociais, Rio de Janeiro, vol. 61, n 3, 2018 
O modelo para as despesas com obras confirma a forte influência do período eleitoral já identificada nas estimações anteriores, mais destacadamente naquelas relacionadas às despesas de capital e investimentos. Os resultados apresentados na coluna (1) mostram que todas as variáveis dummies para os anos não eleitorais mostraram-se altamente significativas. As despesas no ano anterior à eleição (DAE) com obras, são cerca de $7,00 \%$ inferiores do que no ano eleitoral, enquanto nos anos seguintes caem 18,43\% (DDE) e 14,51\% (DDDE), o que, mais uma vez, sugere comportamentos oportunistas dos governantes no país. Também foi constatada uma tendência de expansão nos gastos em obras de $2,36 \%$ ao longo dos anos.

Não obstante, não foi identificada influência do componente ideológico-partidário nas despesas com obras, o que sugere que, independente das bandeiras e eventuais programas que defendam, os partidos dos diferentes matizes possuem um comportamento similar e oportunista no que se refere aos gastos com obras, promovendo a expansão dos gastos em anos de eleição, com provável interesse em obter vantagens nos resultados eleitorais.

Ainda mais acentuados são os resultados para as despesas de Urbanismo ilustrados na coluna (2) da tabela 3. O resultado encontrado aponta que nos anos pré-eleitorais (DAE) as despesas são 19,43\% inferiores, enquanto nos anos seguintes eles reduzem primeiro em 22,13\% (DDE) e depois em 16,56\% (DDDE), em comparação com os anos eleitorais.

Também para as despesas com Urbanismo as variáveis que representam os efeitos ideológico-partidários não se mostraram significativas. Isso sugere novamente que não há diferença importante que distinga os partidos em relação à execução dos orçamentos estaduais voltados para as despesas com urbanismo. Os partidos em geral seguem uma postura oportunista vinculados ao calendário eleitoral e à maximização de votos.

Os resultados das estimações permitem concluir, de um modo geral, que há presença de ciclos políticos orçamentários na execução das despesas públicas dos estados brasileiros. Essa presença mostrou-se mais acentuada nas despesas relacionadas a investimentos como aquelas destinadas a obras e urbanismo. Tal conclusão encontra respaldo na teoria econômica, notadamente na Teoria dos Ciclos Político-Econômicos apresentada por Nordhaus (1975) e Rogoff (1987), sendo identificado o comportamento oportunista na condução das despesas orçamen- 
tárias dos estados, que tendem a se expandir nos anos eleitorais e se contrair ao longo dos anos pós-eleitorais.

Tais resultados encontram ainda correspondência com aqueles descritos pelos seguintes estudos: Drazen e Eslava (2003), encontraram um crescimento de cerca de $6,0 \%$ nos gastos totais e de $16 \%$ naqueles com investimentos, em anos eleitorais nos estados da Colômbia; Gámez e Ibarra-Núnez (2009), também identificaram comportamento cíclico para os gastos em estados mexicanos, com expansão de cerca de 2,00\% nos gastos totais em anos eleitorais; Veiga (2004) detectou evidências de ciclos políticos orçamentários nos municípios portugueses, nos quais se constatou empiricamente que há ampliação de déficits municipais e das despesas, especialmente as despesas com investimento, em anos eleitorais; em Sakurai e Gremaud (1997), as estimações observaram impulsos positivos nos gastos em anos eleitorais para as despesas totais e correntes para o municípios paulistas; o artigo de Sakurai (2009), sugeriu um efeito composição dos orçamentos municipais em anos eleitorais, com expansão nas funções de despesas como saúde e saneamento e habitação e urbanismo, não tendo assinalado, contudo, o mesmo padrão para o caso das despesas com educação; Bittencourt (2002), igualmente detectou a manifestação dos ciclos na execução das despesas dos estados do Brasil entre 1983 e 2000, com resposta ao período eleitoral, descrevendo como mais intensos os efeitos sobre as despesas com transportes e habitação e urbanismo; Araújo (2010), apontou forte intensidade do efeito dos ciclos eleitorais sobre gastos dos estados brasileiros com despesas de custeio, capital, educação e saúde.

Por outro lado, não foi identificada uma diferença substantiva na condução do orçamento público entre os partidos que pertencem a grupos ideológicos distintos. Dentre as dez variáveis analisadas, apenas três despesa total, despesas correntes e educação - indicaram que o viés ideológico-partidário possa afetar a forma como os gastos públicos são direcionados. Todavia, esse fator não apresentou grande relevância: os gastos totais e as despesas correntes dos partidos de direita foram de $1,7 \%$ e 3,0\% inferiores; e, os gastos com educação foram cerca de 5,0\% inferiores para os partidos de centro ao longo dos mandatos, em relação aos partidos de esquerda.

Os resultados relativamente baixos do impacto do componente ideológico partidário, identificados nos modelos apresentados neste traba-

DADOS - Revista de Ciências Sociais, Rio de Janeiro, vol. 61, n 3, 2018 
Daniel Guerra, Adriano Nascimento da Paixão e Paulo Amilton Maia Leite Filho

lho contrastam com os divulgados em Araújo (2010), que localizou forte viés ideológico na gestão dos gastos públicos estaduais. Todavia, encontra confluência ao que foi descrito em Sakurai e Gremaud (1997), Bittencourt (2002) e Sakurai (2009).

\section{CONSIDERAÇÕES FINAIS}

Os resultados evidenciaram a presença de CPE nos gastos públicos em âmbito estadual no Brasil, seguindo, em termos gerais, os pressupostos delineados pelo modelo oportunista. Restou demonstrado que os gastos públicos são ampliados nos anos eleitorais em comparação com os demais anos dos mandatos, confirmando-se a hipótese adotada.

A presença da influência do calendário eleitoral na evolução dos gastos públicos foi observada de forma mais contundente em algumas funções despesas específicas, quais sejam, despesas de capital, investimentos, obras e urbanismo. Algumas razões podem explicar tal resultado: primeiro, existem limitações de ordem legal que restringem e vinculam as despesas públicas reduzindo o grau de discricionariedade dos gastos; segundo, que os gastos em obras públicas e sua inauguração próxima ao período eleitoral, como geralmente ocorre, possuem, aparentemente, maior apelo eleitoral, posto serem as obras mais tangíveis e observáveis aos eleitores do que gastos realizados com educação, por exemplo. Essa segunda inferência é reforçada com o resultado de que os governantes que concorreram a reeleições gastaram ainda mais com despesas de capital e investimentos e menos em educação em anos eleitorais do que aqueles que não disputaram a reeleição. Esses resultados guardam proximidade com aqueles apresentados em Drazen e Eslava (2003), Gámez e Ibarra-Núnez (2009), Veiga (2004), Sakurai e Gremaud (1997), Sakurai (2009) e Bittencourt (2002).

No que se refere especificamente ao teste quanto à existência de diferença na gestão dos gastos estaduais pelos diferentes grupos ideológicos partidários, observou-se que não há uma diferença importante que distinga esses grupos no Brasil. Dentre as dez variáveis analisadas apenas três - despesa total, despesas correntes e educação - indicaram que o viés ideológico-partidário afeta a forma como os gastos públicos são direcionados, porém, com impacto pouco relevante. No período analisado, os gastos totais e as despesas correntes dos partidos de direita foram de 1,7\% e 3,0\% inferiores enquanto, os gastos com educação foram cerca de $5,0 \%$ inferiores para os partidos de centro ao longo dos 
mandatos, em relação aos partidos de esquerda. Esse resultado, embora conflite com o enunciado pelo modelo partidário de Hibbs (1977), de certo modo já poderia ser esperado para o Brasil e corrobora a ideia de que há pouca consistência ideológica por parte dos partidos políticos do país. Resultados semelhantes a esse respeito foram encontrados em Sakurai e Gremaud (1997), Bittencourt (2002) e Sakurai (2009).

Assim, pode-se concluir que, para a amostra selecionada, é possível asseverar que a realização dos gastos públicos estaduais no Brasil é afetada pelo calendário eleitoral, oscilando de maneira cíclica conforme previsto na teoria dos Ciclos Político-Econômicos. Tal comportamento ocorre de forma indistinta entre os governos, que aceleram as despesas no último ano dos mandatos, ou seja, nos anos em que há eleições, independentemente do grupo ideológico-partidário em que estejam inseridos os seus governantes.

Embora os objetivos da pesquisa tenham sido alcançados, o campo abrangido pela Teoria de Ciclos Político-Econômicos ainda permite outras nuances e aprofundamentos em futuras investigações. Primeiro, seria relevante, havendo disponibilidade de dados e informações, desagregar ainda mais os dados para observar em qual tipo de gastos se dá a maior influência do calendário eleitoral na execução orçamentária. Outra possibilidade, para a pesquisa de ciclos políticos orçamentários, seria adotar a regionalização para níveis municipais ou nacionais; poder-se-ia, ainda, avaliar a condução fiscal dos países no geral, podendo-se considerar os efeitos espaciais ou características como faixas de renda e/ ou grau de desenvolvimento e maturidade das democracias e instituições.

Outras indagações poderiam ser objeto de novas investigações tais quais: em que medida e em qual direção o oportunismo na condução das despesas públicas influencia o resultado eleitoral? Se há influência, quais áreas e tipos de despesas rendem mais votos? O nível de informação da sociedade, por meio de jornais, revistas, internet e do grau de transparência dos gastos públicos afetam a forma como são gastos e o destino dos gastos públicos? O maior grau de informação da sociedade poderia condenar aqueles que agissem de forma oportunista? Como a dimensão e a composição dos ciclos políticos orçamentários dependem das características institucionais do país? Há perda de 
eficiência quando da execução cíclica do orçamento? Enfim, muitas questões ainda podem ser levantadas e indicar novas abordagens de pesquisa.

Recebido para publicação em 18 de julho de 2016 Reapresentado em 2 de novembro de 2017

Reapresentado em 25 de abril de 2018 Aprovado para publicação em 2 de outubro de 2018 
Os Ciclos Político-Econômicos e os Gastos dos Estados no Brasil: 1995-2013

\section{REFERÊNCIAS BIBLIOGRÁFICAS}

ALESINA, Alberto. (1987). “Macroeconomic Policy in a Two-Party System as a Repeated Game". Quartely Jornal of Economics, 102, 651-78.

; ROUBINI, Nouriel; COHEN, Gerald. (1997), Political Cycles and the Macroeconomy. MIT Press.

ARAÚJO, Jevuks Matheus de. (2010), Relações Entre Economia E Política: Uma Análise Dos Ciclos Político-Econômicos Nos Estados Brasileiros No Período de 1995 a 2008. Dissertação (Mestrado em Economia), Universidade de Federal da Paraíba. João Pessoa.

ARAUJO JUNIOR, Ari. F.; CANÇADO, Paulo L.; SHIKIDA, Cláudio D. (2005), “Economics and Politics: o que determina as chances de reeleição em municípios? O caso das eleições municipais de Minas Gerais -2000". Informe Gepec, Toledo (PR), v. 09, no 2 .

ARROW, Keneth J. (1951), Social Choice and Individual Values. New York: wiley, Chapman \& Hall.

BITTENCOURT, Jeferson. L. (2002), Evidências De Ciclo Político na Economia Brasileira: Um Teste para a Execução Orçamentária dos Governos Estaduais - 1983/2000. Dissertação (Mestrado em Ciências Econômicas), Universidade Federal do Rio Grande do Sul, Porto Alegre.

BORSANI, Hugo. (2001), “Eleições e Desempenho Macroeconômico na América Latina (1979-1998)". DADOS - Revista de Ciências Sociais, Rio de Janeiro, Vol. 44, no 3, pp. 481-512.

. (2004), “Relações entre Política e Economia: Teoria da Escolha Pública”. In: Economia do Setor Público no Brasil. BIDERMAN, Ciro; ARVATE, Paulo (org.). Editora Campus. Rio de Janeiro - RJ.

BRASIL. (2005), Lei de Responsabilidade Fiscal: Lei Complementar no 101, de 4 de maio de 2000. 4. Reimpr. - Brasília: Senado Federal, Subsecretaria de Edições Técnicas, 2005.

BURDEKIN, Richard C. K. (1985), Fluctuations in U.S. Voting Behavior: Evidence from Presidential Elections. Research Paper n. 8506, Federal Reserve Bank of Dallas outubro.

CARRILlO, Paúl A. (2012), “Los Ciclos Políticos Económicos em Ecuador: 1993-2010”. Departamento de Estudios Tributários, Centro de Estudios Fiscales, Servicio de Rentas Internas, Quito, Ecuador, junho.

COPPEDGE, Michael. (1997), "A Classification of Latin American Political Parties". Kellogg Institute Working Paper 244.

COSTA, Mylena M. de Alencastro. (2006), Reeleição e Política Fiscal: um estudo dos efeitos da reeleição nos gastos públicos. Dissertação (Mestrado em Economia do Setor Público), Brasília, Universidade de Brasília.

COSSIO, Fernando A. B. (2001), “O comportamento Fiscal dos Estados Brasileiros e seus Determinantes Políticos". Economia, v. 2, no 1, pp. 207-258.

DADOS - Revista de Ciências Sociais, Rio de Janeiro, vol. 61, n 3, 2018 


\section{Daniel Guerra, Adriano Nascimento da Paixão e Paulo Amilton Maia Leite Filho}

DOWNS, Anthony. (1957), Aneconomic theory of democracy. New York: Harper Collins Publischers.

DRAZEN, Allan. (2000), “The Political Business Cycle After 25 years". NBER, University of Maryland, Hebrew University of Jerusalem, pp. 75-137.

_ ;ESLAVA, Marcela. (2003), “The Political Business Cycle in Colombia on the National and Regional level". Archivos de Economia 003616, Departamento Nacional de Planeaciòn.

. (2008a), "Political Business Cycles". in Steven N. Durlauf and Lawrence E. Blume (eds.). The New Palgrave Dictionary of Economics. 2a ed. Palgrave: Macmillan,.

. (2008b), "Political Budget Cycles". in Steven N. Durlauf and Lawrence E. Blume (eds.). The New Palgrave Dictionary of Economics. 2a ed. Palgrave: Macmillan,.

FAIR, RAY C. (1996), “Econometric and Presidential Elections". Jornal of Economic Perspectives - vol. 10, no 3 - pp. 89-102.

FEREJOHN, John. (1986), "Incumbent Performance and Electoral Control". Public Choice, no 50 , pp. 5-25.

FIALHO, Tânia. M. M. Performance Macroeconômica e Política: Análise da Evidência de Ciclos Políticos no Brasil - 1953-1995. (1996), Dissertação (Mestrado em de Desenvolvimento e Planejamento Regional), Belo Horizonte, Universidade Federal de Minas Gerais.

. (1997), "Testando a evidência de ciclos políticos no Brasil". RBE, vol. 51, no 3, jul/set., pp. 379-89.

GÁMEZ Cesáreo; IBARRA-YÚNEZ, Alejandro. (2009), "El ciclo político oportunista y el gasto de los estados mexicanos". Gestión y Política Pública, vol. XVIII, no 1, 1ํsemestre.

GERBER, Alan. (1998), "Estimating the effect of campaign spending on senate election outcomes using instrumental variables". American Political Science Review, vol. 92, pp. 401-411.

GIAMBIAGI, Fabio; ALÉM, Ana Cláudia. (2008), Finanças Públicas - Teoria e Prática no Brasil. 3. ed. Rio de Janeiro, Elsevier.

GIUS, Mark. (2009), "The Effects of Campaign Expenditures on Congressional Elections". American Review of Political Economy. vol. 7 no 1/2. jun/dez., pp. 51-66.

GREENE, William. H. Econometric Analysis. New Jersey: Prentice Hall, 2000.

GROSSMAN, Gene M.; HELPMAN, Elhanan. (1996), "Electoral Competition and Special Interest Politics". Review of economic studies. Vol. 63, PP. 265-286, 1996.

GUJARATI, Damodar N. (2000), Econometrica Básica. 3a Ed. São Paulo, Pearson Makron Books.

HIBBS Jr, DOUGLAS A. (1977), "Political Parties and Macroeconomic Policy”. American Political Science Review, vol. 71, pp. 1467-1487.

JACOBSON, Gary C.; KERNELL, Samuel. (1983), “Strategy and Choice in Congressional Elections". [S.1.]: Yale University Press. 
Os Ciclos Político-Econômicos e os Gastos dos Estados no Brasil: 1995-2013

. (1990), “The Effects of Campaign Spending in Election Outcomes: New Evidences for Old Arguments". American Journal of Political Science, vOL. 34, pP. 334-362.

JULA, Dorin; JULA, Nicoleta. (2007), "Political Budget Cycles in the Romanian Regions. Institute for Economic Forecasting, University of Bucharest, Bucharest, pp. 1-18.

KRAMER, Gerald H. (1971), “Short-term Flutuation in U.S. Voting Behavior, 1896-1964”. American Political Science Review, vol. 65, pp. 135-143.

LARRAÍN, Felipe; ASSAEL, Paola. (1995), “Cincuenta Años de Ciclo Político-Economico em Chile". Cuadernos de Economía, ano 32, no 96, pp. 129-150.

LÓPEZ, Maurício, GALLÓN, Santiago; FRESARD, Christian. (2002), “El Ciclo Político-Económico en Colombia, 1925-1999”. Lecturas de Economía, vol. 56, no 56, pp. 7-30.

MATIAS-PEREIRA, José. (2006), Finanças públicas: a Política Orçamentária no Brasil. 3a ed. São Paulo: Atlas.

MENDES, Marcos; ROCHA, Carlos A. A. (2004), "O que reelege um Prefeito?" Consultoria Legislativa do Senado Federal. Brasília Textos para Discussão 7. Brasília, abril.

MENEGUIN, Fernando. B.; BUGARIN, Maurício S. (2001), "Reeleição e Política Fiscal: Um Estudo dos Efeitos da Reeleição nos Gastos Públicos". Revista de Economia Aplicada, FEA-USP /FIPE, vol. 5, no 3, pp. 601-622.

NAKAGUMA, Marcos Y. (2006), Ciclos políticos e resultados eleitorais: um estudo sobre o comportamento do eleitor brasileiro. Dissertação (Mestrado em Economia), Universidade de São Paulo, São Paulo.

NORDHAUS, Willian. (1975), “The Political Business Cycle”. Review of Economic Studies, no 42 , pp.169-190.

PEREIRA, André Luiz Greve; FERNANDEZ, José. C. (2007), A influência das transferências voluntárias na reeleição dos prefeitos e no desenvolvimento dos municípios baianos. In: Encontro Nacional de Economia - ANPEC, 2007, Recife. Encontro Nacional de Economia 2007 - ANPEC, 2007

PERSON, Torsten; TABELLINI, Guido. (1990), “Macroeconomic Policy, Credibility, and Policitcs". Harwood Academic Publisher.

PETTERSSON-LIDBOM, Per. (2000). "A test of the rational electoral-cycle hypothesis". In Pettersson, P. (Ed.), Elections, Party Politics and Economic Policy, Monograph Series, № 40, IIES, Stockholm University.

POWER, Timothy; ZUCCO, Cesar. (2008), “Estimating Ideology of Brazilian Legislative Parties, 1990-2005: A Research Communication". Latin American Review, vol. 44, no 1,pp.218-246.

PREUSSLER, Athos. P. S. (2001), Um estudo empírico dos ciclos político-econômicos no Brasil. Dissertação (Mestrado em Economia), Universidade Federal do Rio Grande do Sul, Porto Alegre.

; PORTUGAL, Marcelo. S. (2002), “Um estudo empírico dos ciclos político-econômicos no Brasil. Textos para Discussão, no 5, pp. 1-17. Programa de Pós-Graduação em Economia, Universidade Federal do Rio Grande do Sul.

DADOS - Revista de Ciências Sociais, Rio de Janeiro, vol. 61, n 3, 2018 


\section{Daniel Guerra, Adriano Nascimento da Paixão e Paulo Amilton Maia Leite Filho}

QUEIROZ, Mario C. L.; BITTENCOURT da Silva, Almir. (2010), “Ciclos Políticos Orçamentários no Estado do Ceará (1986 - 2006)". Planejamento e Politicas Publicas, vol. 35, pp. 223-254.

RODRIGUES, Leôncio M. (2002a), Partidos, ideologia e composição social: um estudo das bancadas na Câmara dos Deputados. São Paulo: Edusp.

. (2002b), “Partidos, Ideologia e Composição Social”. Revista Brasileira de Ciências Sociais, vol. 17, pp. 31-47.

ROGOFF, Kenneth. (1987), “Equilibrium Political Budget Cycles”. National Bureau of Economic Research, Working Paper no 2428, Cambridge, pp. 1-35.

. (1990), "Equilibrium Political Budget Cycles". American Economic Review, vol. 80, ำ 1 .

; SILBERT, Anne. (1998), "Election and Macroeconomic Policy Cycles". Review of Economic Studies, vol. 55, o 1.

ROTH, Roy K. (2012), “Does the Economy Determine the President? A Regression Model for Predicting US Presidential Elections". Undergraduate Economic Review. vol. 9, no 1, (Artigo).

SAKURAI, Sérgio. N.; MENEZES FILHO, Naércio A. (2007), Política Fiscal e Reeleição nos Municípios Brasileiros: uma Análise via Dados em Painel para o Período 1988-2000. Apresentado no 35 Encontro Nacional De Economia, ANPEC. 4-7 de dezembro.

GREMAUD, Amaury. P. (2007), “Political Business Cycles: Evidencias Empíricas para os Municípios Paulistas (1989 - 2001)”. Economia Aplicada, vol. 11, № 1, pp. 27-54..

; (2009), “Ciclos Políticos nas Funções Orçamentárias dos Municípios Brasileiros: Uma Análise para o Período 1990-2005 via Dados Em Painel". Estudos Econômicos, vol. 49 , no 1, jan/mar., pp. 39-58.

SALVATO, Márcio. A. et al. (2007), “Ciclos Políticos: um Estudo sobre a Relação entre Flutuações Econômicas e Calendário Eleitoral no Brasil, 1985-2006. Working Paper no 01. Belo Horizonte: IDHS/PUC-MG.

SAMUELS, David. (1997), “Determinantes do Voto Partidário em Sistemas Eleitorais Centrados no Candidato: Evidências sobre o Brasil". DADOS - Revista de Ciências Sociais, vol. 40, no 3 .

. (2001), "Money, Elections, and Democracy in Brazil". Latin American Politics and Society, vol. 43, n. 2, pp. 27-48.

TAROUCO, G. 2007. Os Partidos e a Constituição: Ênfases Programáticas e Propostas de Emenda. Rio de Janeiro. Tese (Doutorado em Ciência Política). Rio de Janeiro, Instituto Universitário de Pesquisas do Rio de Janeiro - IUPERJ/UCAM.

TAROUCO, Gabriela; MADEIRA, Rafael M. (2015), "Os Partidos Brasileiros Segundo seus Estudiosos: Análise de um Expert Survey". Civitas, Porto Alegre, vol. 15, no 1, jan/mar., pp e25-e39.

. (2013), "Partidos, programas e o debate sobre esquerda e direita no Brasil". Revista de Sociologia e Política, vol.21, no 45, pp. 145-165. 
Os Ciclos Político-Econômicos e os Gastos dos Estados no Brasil: 1995-2013

VALE, Luciana. O.; ARAÚJO, Adriano. F. V.; PAIXÃO, Adriano. N. (2009) “Determinantes das Chances de Reeleição Municipal: o Caso das Eleições Municipais de Tocantins - 2004". In: ENABER, 7. Anais... São Paulo, Aber.

VEIGA, Linda G.; Veiga, Francisco J. (2004), Political Business Cycles at the Municipal Level. Minho, Universidade do Minho.

WOOLDRIDGE, Jeffrey M. Introdução à Econometria: uma abordagem moderna. São Paulo: Cengage Learning, 2014. 
RESUMO

Os ciclos político-econômicos e os gastos dos estados no Brasil: 1995-2013

O objetivo deste trabalho é verificar se existem evidências empíricas de Ciclos Político-Econômicos para os governos estaduais do Brasil, analisando-se as políticas fiscais e os resultados eleitorais no período de 1995 a 2013. Busca-se averiguar se os governos estaduais manipulam os gastos públicos como medida de sinalizar competência diante dos eleitores para com isso ampliar as chances de vitória eleitoral do governante/ partido no poder. Secundariamente será verificado se os gastos são afetados por razões ideológico-partidárias. Foi utilizado como referencial teórico os postulados propostos na Teoria de Ciclos Políticos Econômicos assentados fundamentalmente por Nordhaus (1975), Rogoff (1990), Hibbs (1977) e Alesina (1987). Os resultados evidenciaram a presença de CPE nos gastos públicos a nível estadual no Brasil, seguindo, em termos gerais, os pressupostos delineados pelo modelo oportunista. Os gastos públicos são ampliados nos anos eleitorais em comparação com os demais anos dos mandatos, confirmando-se a hipótese adotada. A presença da influência do calendário eleitoral na evolução dos gastos públicos foi observada de forma mais contundente em algumas funções despesas específicas, quais sejam, despesas de capital, investimentos, obras e urbanismo. Observou-se que não há uma diferença importante que distinga grupos ideológicos na política fiscal dos Estados no Brasil.

Palavras-chave: política fiscal; dados em painel; ciclos político-econômicos; gastos públicos; finanças públicas

\section{ABSTRACT \\ The political-economic cycles and the expenditures of the states in Brazil: 1995-2013}

The goal of the article is to investigate the relationship between political and economic cycles (PEC) and state governments in Brazil, analyzing tax policies and election results from 1995 to 2013. Therefore, the article analyzes state governments manipulation of public spendings in order to indicate government competence to voters and, therefore, to increase the chances of electoral victory of the ruling party. In addition, the article investigates whether expenditures are influenced by ideological-partisan reasons. As theoretical reference the article uses postulates proposed by the Theory of Economic Political Cycles settled fundamentally by Nordhaus (1975), Rogoff (1990), Hibbs (1977) and Alesina (1987). As empirical results the article reveals 
the presence of CPE in state expenditures in Brazil following, in general, the assumptions outlined by the opportunistic model. Public spending is expanded in electoral years compared to the other years of the mandates, confirming the hypothesis outlined in the article. The presence of the influence of the electoral calendar on the evolution of public spending was observed more forcefully in some specific expenditure functions, such as capital expenditures, investments, works and urbanism. It was observed that there is not an important difference that distinguishes ideological groups in the fiscal policy of the States in Brazil.

Keywords: fiscal policy; panel data; political-economic cycles; Public spending; public finances.

\section{RÉSUMÉ}

Les cycles politico-économiques et les dépenses des états au Brésil: 1995-2013

L'objectif de cet article est vérifier l'existence des évidences empiriques de cycles politico-économiques pour les gouvernements des états brésiliens en analysant les politiques fiscales et les résultats des élections entre 1995 et 2013. On veut vérifier si les gouvernements des états manipulent les dépenses publiques pour présenter ses aptitudes aux électeurs de façon à augmenter ses chances électorales et de son parti. Deuxièmement, on veut établi si les dépenses sont affectées par des raisons idéologiques et partisanes. Les postulats proposés par la Théorie des cycles politico-économiques établie par Nordhaus (1975), Rogoff (1990), Hibbs (1977) et Alesina (1987) sont utilisés comme référence théorique. Les résultats mis en évidence la présence de CPE dans les dépenses de les états au Brésil, à la suite, en général, des hypothèses exposées par le modèle opportuniste. Les dépenses publiques sont augmentées les années électorales par rapport aux autres années de mandat, confirmant l'hypothèse. La présence de l'influence du calendrier électoral sur l'évolution des dépenses publiques est observée notamment dans des dépenses spécifiques comme l'investissement en capital, financiers, en la construction publique et en l'urbanisme. Par contre, il n'existait pas des différences importantes entre les groupes idéologiques dans la politique fiscale des états au Brésil.

Mots-clés: politique fiscale ; données de panel ; cycles politico-économiques ; dépenses publiques ; finances publiques

DADOS - Revista de Ciências Sociais, Rio de Janeiro, vol. 61, n-3, 2018 


\section{RESUMEN}

Los ciclos político-económicos y los gastos de los estados en Brasil: 1995-2013

El artículo verifica si hay evidencias empíricas de Ciclos Político-Económicos (CPE) para los gobiernos estaduales de Brasil, analizando las políticas fiscales y los resultados electorales entre 1995 y 2013. Se busca averiguar si los gobiernos estaduales manipulan los gastos públicos como medida de señalar capacidad ante los electores para con ello ampliar las posibilidades de victoria electoral del gobernante/partido en el poder. Secundariamente se verificará si los gastos se ven afectados por razones ideológicas-partidarias. Se utilizó como referencial teórico los postulados propuestos en la Teoría de Ciclos Políticos Económicos asentados fundamentalmente por Nordhaus (1975), Rogoff (1990), Hibbs (1977) y Alesina (1987). Los resultados evidenciaron la presencia de CPE en los gastos públicos a nivel estadual en Brasil, siguiendo, en términos generales, los presupuestos delineados por el llamado modelo oportunista. Los gastos públicos se amplían en los años electorales en comparación con los demás años de los mandatos, confirmándose la hipótesis adoptada. La presencia de la influencia del calendario electoral en la evolución del gasto público fui observada de forma más contundente en algunas funciones gastos específicos, como gastos de capital, inversiones, obras y urbanismo. Se observó que no hay una diferencia importante que distinga grupos ideológicos en la política estadual.

Palavras-clave: política fiscal; datos en panel; ciclos político-económicos; gastos públicos; finanzas públicas 


\section{ERRATA}

Na página 695, Onde se lia:

"Daniel Guerra"

Ministério Público do Estado da Paraíba. João Pessoa, PB, Brasil. (e-mail: danieleconomia@hotmail.com)

Leia-se:

“Daniel Guerra" ${ }^{1}$ Adriano Nascimento da Paixão² e Paulo Amilton Maia Leite Filho ${ }^{3 \prime \prime}$

${ }^{1}$ Ministério Público do Estado da Paraíba. João Pessoa, PB, Brasil. (e-mail: danieleconomia@hotmail.com);

${ }^{2}$ Universidade Federal da Paraíba. João Pessoa, PB, Brasil. (e-mail: anpaixao@gmail.com);

${ }^{3}$ Universidade Federal da Paraíba. João Pessoa, PB, Brasil. (e-mail: pmaiaf@hotmail.com)

Na página 695, Onde se lia:

"http:/ / dx.doi.org/10.1590/001152582018157"

Leia-se:

“http:/ dx.doi.org/10.1590/001152582018171"

DADOS - Revista de Ciências Sociais (2018), vol. 61, no 3: E3-E5 